\title{
Desenvolvimento do pensamento crítico por meio do estudo de lógica argumentativa na alfabetização científica
}

\author{
Development of critical thinking through the study of argumentative \\ logic in scientific literacy

\section{Desarrollo del pensamiento crítico a través del estudio de la lógica argumentativa en la alfabetización científica}

\author{
Pablo João Canal da Costa (pablojoaoc@gmail.com) \\ Universidade de Passo Fundo - UPF
}

Bianca Possel (bianca.possel@gmail.com)

Universidade de Passo Fundo - UPF

Armando Foscarin (135303@upf.br)

Universidade de Passo Fundo - UPF

Cleci T. Werner da Rosa (cwerner@upf.br)

Universidade de Passo Fundo - UPF

Resumo: A pandemia causada pelo coronavírus, durante o ano de 2020, explicitou um problema nas redes: a disseminação de notícias falsas, as chamadas fake news, informações incorretas e argumentos falaciosos que tentaram minar a opinião pública. Tais argumentos constituem-se muitas vezes como informações pseudocientíficas, ou seja, que apesar de não possuírem validade, tentam passar-se por cientificamente aceitos, bem como argumentos anticientíficos, que simplesmente negam toda à razão e bom senso visando atacar a ciência. Partindo deste contexto, é possível que o estudo de lógica argumentativa voltado à Alfabetização Científica entre os jovens, possa ser um recurso para preparar os jovens criticamente para o contato com a desinformação, ou seja, para torná-los alfabetizados cientificamente. Buscando-se discutir esse tema, o presente artigo apresenta na forma de um ensaio aspectos bibliográficos que possam estabelecer um diálogo entre a alfabetização científica e a lógica filosófica. A partir das reflexões decorrentes desse estudo, considera-se que a lógica argumentativa possa vir a colaborar com o processo de alfabetização científica em jovens e crianças, ajudando a desenvolver pensamento crítico e reflexivo frente às artimanhas pseudocientíficas tão disseminadas na contemporaneidade.

Palavras-chave: ciência e pseudociência; argumentação; ensino de ciências.

Abstract: The pandemic caused by the coronavirus, during the year 2020, spelled out a problem on the networks: the spread of false news, the so-called fake news, incorrect information and fallacious arguments that tried to undermine public opinion. Such arguments are often constituted as pseudo-scientific information, that is, that although

Recebido em: 30/05/2021

Aceite em: 13/08/2021 
they have no validity, they try to pass themselves off as scientifically accepted, as well as anti-scientific arguments, which simply deny all reason and common sense in order to attack science. From this context, it is possible that the study of argumentative logic aimed at Scientific Literacy among young people, can be a resource to prepare young people critically for contact with disinformation, that is, to make them scientifically literate. Seeking to discuss this topic, this article presents bibliographical aspects in the form of an essay that can establish a dialogue between scientific literacy and philosophical logic. Based on the reflections arising from this study, it is considered that the argumentative logic may come to collaborate with the process of scientific literacy in young people and children, helping to develop critical and reflective thinking in the face of the pseudo-scientific tricks so widespread in contemporary times.

Keywords: science and pseudoscience; argumentation; science teaching.

Resumen: La pandemia provocada por el coronavirus, durante el año 2020, deletreó un problema en las redes: la difusión de noticias falsas, las llamadas fake news, información incorrecta y argumentos falaces que intentaron socavar la opinión pública. Tales argumentos se suelen constituir como información pseudocientífica, es decir, que aunque no tienen validez, intentan hacerse pasar por científicamente aceptados, así como argumentos anticientíficos, que simplemente niegan toda razón y sentido común para atacar a la ciencia. Desde este contexto, es posible que el estudio de la lógica argumentativa orientada a la Alfabetización Científica entre los jóvenes, pueda ser un recurso para preparar a los jóvenes críticamente para el contacto con la desinformación, es decir, alfabetizarlos científicamente. Buscando discutir este tema, este artículo presenta aspectos bibliográficos en forma de ensayo que puede establecer un diálogo entre la alfabetización científica y la lógica filosófica. A partir de las reflexiones resultantes de este estudio, se considera que la lógica argumentativa puede colaborar con el proceso de alfabetización científica en jóvenes y niños, ayudando a desarrollar el pensamiento crítico y reflexivo ante los trucos pseudocientíficos tan extendidos en la actualidad.

Palabras-clave: ciencia y pseudociencia; argumentación; enseñanza de las ciencias.

\section{INTRODUÇÃO}

Diante do contexto de advento das redes sociais, onde também cada vez mais as pessoas têm acesso a publicar e compartilhar informações, vemos que muitas vezes essas mesmas informações carecem de acuracidade. A pandemia causada pelo coronavírus, no ano de 2020, explicitou um problema nas redes: A disseminação de notícias falsas, as chamadas fake news, informações incorretas e argumentos falaciosos que tentaram minar a opinião pública, fazendo parte da população mais leiga frente a temas e conceitos científicos, desacreditarem nas orientações de autoridades mundiais na área da saúde, e ao invés disso, acreditar em informações provenientes de fontes 
duvidosas. O conceito de fake news tem sido objeto de discussão na literatura, porém em Meneses (2018) encontramos uma tentativa de definição: "um documento deliberadamente falso, publicado online, com o objetivo de manipular os consumidores". O autor opta por utilizar a palavra "documento" ao invés de texto como forma de englobar recursos e ferramentas como vídeos, fotos e outros; por sua vez, a expressão "deliberadamente falso" é justificada em virtude de que o apresentado pode ser total ou parcialmente uma mentira e quem produzir o documento sabe disso; em relação a associação com o "online" é tido como um fenômeno difícil de ser dissociado, pois são as redes sociais ou páginas de blog, programas de notícias, que a dissemina rapidamente.

Falácia é um termo que na sua lógica e retórica é incoerente, mesmo que possua aparência de verdadeiro (COPI, 1981). Em geral, em uma expressão falaciosa as premissas do argumento não sustentam a conclusão. Algumas delas são difíceis de serem percebidas, e, muitas vezes, terminam passando-se por argumentos válidos para parte da população. É o caso das fake news que recorrem a fatos e acontecimentos reais, porém com uma interpretação enviesada, distorcendo o conteúdo. Essas são comumente utilizadas para embasar argumentos pseudocientíficos, como os que negam o aquecimento global e as vacinas, por exemplo.

Tal entendimento sustenta a ideia central desse texto, que pretende contribuir argumentativamente com a premissa de que o estudo de lógica pode contribuir para o desenvolvimento do pensamento crítico na área de alfabetização científica frente às desinformações pseudocientíficas que minam o senso comum. Estudar lógica argumentativa voltado à Alfabetização Científica pode ser um caminho que nos leva a compreender melhor nossa própria forma de receber e elaborar argumentos científicos. O texto, produzido a partir das discussões em uma disciplina de Alfabetização Científica de um programa de pós-graduação, apresenta um caráter de ensaio apoiandose para sua estruturação, em materiais bibliográficos como livros e artigos a respeito de alfabetização científica e lógica filosófica. Para tanto, estruturamos o texto em seções que buscam trazer o entendimento de alfabetização científica e sua relação com a ciência e pseudociência; a lógica argumentativa em aproximação com o pensamento e a falácia; e, ao final tecer possibilidades frente ao entrelaçamento desses dois aspectos e suas contribuições para a formação dos jovens.

Recebido em: 30/05/2021

Aceite em: 13/08/2021 


\title{
2. AlFABETIZAÇÃo CIENTÍFICA, CIÊNCIA E PSEUdOCIÊNCIA
}

No Brasil, é possível encontrar nos Parâmetros Curriculares Nacionais (PCNs) voltado ao Ensino Fundamental que "a formação de um cidadão crítico exige sua inserção numa sociedade em que o conhecimento científico e tecnológico é cada vez mais valorizado" (BRASIL, 1997, p. 15), tarefa esta que envolve processos relacionados à alfabetização científica. O que é reforçado para esse mesmo nível de escolarização pela Base Nacional Comum Curricular (BRASIL, 2018, p. 54), ao mencionar que o ensino deve promover situações que favoreçam o:

\begin{abstract}
estímulo ao pensamento criativo, lógico e crítico, por meio da construção e do fortalecimento da capacidade de fazer perguntas e de avaliar respostas, de argumentar, de interagir com diversas produções culturais, de fazer uso de tecnologias de informação e comunicação, possibilita aos alunos ampliar sua compreensão de si mesmos, do mundo natural e social, das relações dos seres humanos entre si e com a natureza.
\end{abstract}

Em ambos os documentos citados identificamos que a presença da discussão sobre a alfabetização científica embora possa aparecer com o nome de letramento científico. Sobre o uso dos dois termos, Sasseron e Carvalho (2011, p. 60) relatam que ambos constituem tema de um mesmo objetivo no sistema educacional.

Podemos perceber que no cerne das discussões levantadas pelos pesquisadores que usam um termo ou outro estão as mesmas preocupações com o ensino de Ciências, ou seja, motivos que guiam o planejamento desse ensino para a construção de benefícios práticos para as pessoas, a sociedade e o meio-ambiente.

Em relação ao termo "alfabetização" no contexto da Alfabetização Científica, as mesmas autoras colocam que esta deve ser capaz de desenvolver em alguém a capacidade de organizar seu pensamento de maneira lógica, auxiliando na construção de uma consciência crítica em relação ao mundo que vive. Sustentam essa ideia de alfabetização a partir dos escritos de Paulo Freire (1980), que diz que a alfabetização deve ser mais que um domínio psicológico e automático de técnicas de ler ou de escrever, mas um domínio consciente que envolva uma autoformação capaz de fazer alguém modificar e influir no seu próprio meio.

Desta forma, Sasseron e Carvalho (2011, p. 75) colocam que a Alfabetização Científica "encontra base, respaldo e consistência na percepção da necessidade emergente de formar alunos para atuação na sociedade atual, largamente cercada por artefatos da sociedade científica e tecnológica". Em outras palavras, como expresso por Rosa, Rosa e Uzeda (2019, p. 127-128) sobre o papel do letramento ou alfabetização científica, "é que ele possa contribuir para a formação de cidadãos com uma base sólida

Recebido em: 30/05/2021

Aceite em: 13/08/2021 
de conhecimentos científicos, possibilitando a tomada de decisão de forma consciente e comprometida com questões éticas, sociais e humanas".

Sem passar por um processo de alfabetização científica crítica e significativa, é difícil esperar que os jovens estejam preparados para compreender sua relação com os artefatos tecnológicos e o ambiente que os rodeiam. Em um contexto assim, é possível que fiquem mais suscetíveis a acreditar em informações disseminadas por inúmeros movimentos pseudocientíficos que se alastram na internet e redes sociais como, por exemplo, os que promulgam a antivacinação, o criacionismo, a teoria da terra plana, a negação do aquecimento global, pandemias, entre outros.

Neste sentido, quando a sociedade falha no processo de tornar os sujeitos alfabetizados cientificamente, não é difícil ver casos como o de pessoas que se utilizam de tecnologias como computadores e smartphones, para até mesmo promover movimentos que negam os próprios conceitos científicos pelos quais essas mesmas tecnologias foram desenvolvidas. É interessante observar que, smartphones, tão utilizados na disseminação de informações anticientíficas, seriam impossíveis de existirem sem eventos como a corrida espacial e a ida do homem à Lua, fato este que curiosamente também é alvo de negação em teorias conspiratórias. Carl Sagan demonstrou preocupação frente a essa questão, afirmando que:

Nós criamos uma civilização global em que os elementos mais cruciais - o transporte, as comunicações e todas as outras indústrias, a agricultura, a medicina, a educação, o entretenimento, a proteção ao meio ambiente e até a importante instituição democrática do voto - dependem profundamente da ciência e da tecnologia. Também criamos uma ordem em que quase ninguém compreende a ciência e a tecnologia. É uma receita para o desastre (SAGAN, 2006, s/p., grifo nosso).

Isso é uma crítica ao modus operandi da sociedade onde, em geral, se oferece uma gama de possibilidades de aquisição de utilitários tecnológicos, como computadores, forno micro-ondas, carros, aviões, etc., mas não na mesma intensidade se dedica à explicação dos princípios científicos que fazem com que essas tecnologias funcionem, ainda que isso esteja de certa forma inserido em conteúdos escolares. Para Sagan (2006), o público tende a abraçar as pseudociências na mesma proporção em que se compreende mal a própria ciência, o que reforça a importância da educação formal para desenvolver a compreensão sobre o método científico desde as mais tenras idades.

Para discutirmos sobre pseudociência e anticiência, aspectos basilares em termos da alfabetização científica, especialmente no contexto de pandemia vivenciado em 2020, retomamos as discussões sobre o que é ciência. Embora ela não possua uma definição única e definitiva, há uma variedade de critérios e conceitualizações que 
podem ser divergentes entre diferentes ciências, como as exatas e naturais em relação às humanas e sociais (FRANCELIN, 2004). Por isso, ao tentar definir o que é ciência, há que haver um cuidado para não tratar como pseudociência, conhecimentos que simplesmente não atendam a todos os critérios relacionados ao fazer ciência presente em uma única perspectiva, como das ciências biológicas ou naturais.

Alguns autores estabelecem critérios que podem ajudar a identificar uma pseudociência. Hansson (2017) coloca dois pontos que comumente aparecem juntos em conhecimentos pseudocientíficos: 1) não são científicos e 2) seus defensores tentam criar a impressão de que são conhecimentos científicos. Na pseudociência haveria, assim, uma intenção deliberada de fazer com que algo que não atenda critérios mínimos de cientificidade se passe por ciência. Para Bunge (1991), “(...) qualquer campo de conhecimento não científico, mas anunciado como científico, será considerado pseudocientífico, ou uma falsa ciência, ou ciência fictícia" (p. 247, tradução nossa ${ }^{1}$ ).

Para exemplificar, podemos dizer que a crença de um cristão em anjos ou de um pajé que habita a Amazônia em espíritos da floresta, ainda que não sejam conteúdos verificáveis cientificamente, não são considerados pseudociência enquanto tratados como questões relativas à fé, religião ou cultura popular. Porém, no momento em que alguém passe a utilizar-se deliberadamente de conceitos teóricos de ciência - como sendo recorrente com os de física quântica - para dizer que a existência de seres sobrenaturais é comprovada cientificamente, estaria aí, então, produzindo um conhecimento pseudocientífico. Isso se dá porque tais conceitos científicos não servem para afirmar fenômenos do tipo, e quando usados neste sentido, provavelmente foram distorcidos. Em outras palavras, usar termos científicos e citar conceitos de física, química, biologia, etc., não é prova de que tal argumento seja de fato científico. Assim como conhecimentos que são parte da cultura popular e tradicional, ainda que não sejam comprovados cientificamente, não são necessariamente pseudocientíficos, a menos que tentem passar-se por ciência sem atender aos critérios de cientificidade necessários para isso.

\footnotetext{
${ }^{1}$ No original: "On the other hand, any field of knowledge that is nonscientific but is advertised as scientific will be said to be pseudoscientific, or a fake or bogus science (...)".
}

Recebido em: 30/05/2021

Aceite em: 13/08/2021 
Um exemplo disso é a pseudociência chamada de teoria do Design Inteligente, onde seus defensores tentam atribuir um caráter de validade e cientificidade ao criacionismo, afirmando terem superado a teoria da evolução Darwiniana. Aqui, tentase encaixar a ciência em um modelo teórico obsoleto a séculos, selecionando apenas dados e informações que corroborem o criacionismo.

Isto chama a atenção para outro aspecto importante que diferencia a ciência da pseudociência, que é o critério popperiano de falseabilidade do conhecimento científico, onde cada descoberta da ciência não se constitui como uma verdade última, mas aceitase que é um conhecimento temporário que poderá ser substituído quando um enunciado seguido de uma contraprova consistente for capaz de refutá-lo (FRANCELIN, 2004). Enquanto a ciência conta com o princípio da incerteza e da possibilidade da mudança de paradigmas, as pseudociências sustentam-se por vezes no que consideram verdades absolutas e inquestionáveis, que quando colocadas à prova, apela-se para desqualificar a ciência. Ao comparar ciência e pseudociência, Sagan fala que:

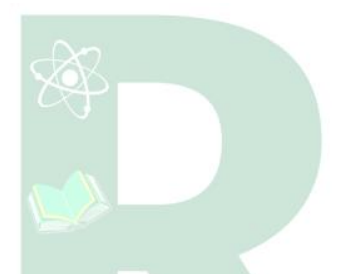

A pseudociência é exatamente o oposto. As hipóteses são formuladas de modo a se tornar invulneráveis a qualquer experimento que ofereça uma perspectiva de refutação, para que em princípio não possam ser invalidadas. Os profissionais são defensivos e cautelosos. Faz-se oposição ao escrutínio cético. Quando a hipótese pseudocientífica não consegue entusiasmar os cientistas, deduz-se que há conspirações para eliminá-la (SAGAN, 2006, s/p.).

Como exemplo disso, há defensores da teoria da Terra plana, que não conseguindo sustentar seus pressupostos diante de evidências realmente científicas, acabam por criar teorias conspiratórias do tipo que a comunidade científica, os governos, a mídia e até as agências espaciais de todo o mundo, estariam em conluio para encobrir a informação de que a Terra seria, na verdade, plana. Neste sentido, alguns movimentos além de pseudocientíficos, tornam-se também anti científicos.

A anticiência, além de tentar passar-se por ciência, como no caso das pseudociências, coloca-se contra a ciência e busca desacreditar a comunidade científica internacional frente à sociedade. Na anticiência observa-se uma rejeição à racionalidade e um desprezo pelo mundo acadêmico-científico, colocando-o como desnecessário para o desenvolvimento do conhecimento, como coloca Sagan (2006, n.p.):

Durante séculos, a ciência tem estado sob uma linha de fogo que, melhor do que pseudociência, pode ser chamada de anticiência. A ciência, a erudição acadêmica em geral, é demasiado subjetiva, afirmam hoje em dia. Alguns até alegam que ela é inteiramente subjetiva, o que também se aplica, dizem eles, à história.

$\mathrm{Na}$ anticiência podemos citar movimentos negacionistas como o antivacina e os que dizem que o aquecimento global não existe. Tais movimentos, além de disseminar 
informações pseudocientíficas, tem potencial de contribuir para o agravamento de problemas como epidemias virais e descaso para com a proteção ao meio ambiente.

Estes movimentos pseudocientíficos e anticientíficos, tem seus pressupostos baseados em falácias argumentativas, algumas das quais abordaremos adiante.

\section{PENSAMENTO, FALÁCIA E ARGUMENTAÇÃO}

O ser humano é composto por pensamentos e intuições, a partir disso, pode emitir julgamentos e premissas argumentativas para convencer alguém sobre algo específico. Quando se está prestes a dissertar sobre um assunto podemos seguir dois caminhos distintos, o primeiro deles é falar de maneira automática, considerando nossas experiências pessoais, coisas que ouvimos ou vemos de outras pessoas, mas tudo isso sem pensar muito, de forma intuitiva e rápida. O segundo caminho é mais lento, porém mais crítico e reflexivo, fazendo com que a afirmação/opinião emitida tenha bases nas quais possa se firmar. Os dois caminhos podem ser chamados de argumentação, entretanto, de acordo com o que escolhemos basear nossas premissas, nossos argumentos serão válidos, ou nem tão válidos assim.

Há anos atrás, antes mesmo de todas as regiões do planeta Terra se tornarem conhecidas, algumas regiões do mapa que ainda não foram exploradas, recebiam uma legenda com o seguinte aviso: aqui há dragões. O nome se devia a circunstância de que algo medonho como um dragão, mesmo não sendo provada sua existência, poderia habitar aqueles lugares desconhecidos. O desconhecido causou e ainda causa o sentimento de medo, mas neste caso, as pessoas poderiam ter um nome do qual chamálo, e, essa explicação fora o suficiente para o incompreensível tornar-se satisfatório.

Em pleno século XXI, dar rótulos simples e satisfatórios para o que não se conhece, é ainda uma prática comum. Vejamos um exemplo: Joana gostaria de emagrecer, e, para isso, apostou em uma das dietas milagrosas que viu na internet. Joana sobe na balança todos os dias no mesmo horário para checar se está dando certo, se o resultado da balança lhe agrada, se enche de alegria e atribui o seu sucesso à dieta; já se o resultado não lhe agrada diz ser devido a flutuação do corpo e segue a dieta. Joana passa meses nessa mesma dieta, mas seu peso segue constante, entretanto, continua a acreditar que ela funciona todas vezes que fica feliz com a balança, quando tem outro Recebido em: 30/05/2021 
resultado, simplesmente o ignora, não dando nenhuma hipótese para um pensamento mais profundo sobre sua dieta ou sobre seu modo de vida. Para a lógica, isso poderia ser denominado como viés de confirmação. O viés de confirmação, segundo Dobelli (2014, p. 31) é o pai de todos os erros de pensamento, pois, é "a tendência de interpretar novas informações de modo que sejam compatíveis com nossas teorias, visões de mundo e convicções". Em outros termos: filtramos novas informações que estão em contradição com nossas visões".

Podemos dizer que Joana acaba nomeando seu dragão, de dieta. As pessoas estão acostumadas a aceitar os dragões da vida, ainda que seja com coisas aparentemente óbvias, elas insistem em se acomodar e não buscar por explicações um pouco mais elaboradas, racionais, aceitáveis do ponto de vista científico. No documentário Aqui há Dragões (Here be Dragons), são mostrados exemplos dos dragões que encontramos no dia a dia, e, a maioria são de medicamentos que prometem aumentar a energia, ajudar a melhorar a memória, curar o estresse, compostos de todas as variedades que dizem curar algo, desde vitamina $\mathrm{C}$ até 'ketchup' orgânico; livros de autoajuda que concedem a receita de como ter uma vida revitalizada e plenamente feliz, diversos estabelecimentos com publicidades que prometem a cura para desconfortos físicos, mentais e até da alma com recursos por vezes duvidosos, ajuda para espantar fantasmas, mau presságios, e, muitas delas, só agem de acordo com o que o horóscopo do jornal previu para seu signo.

Todas essas situações, quando acompanhadas de termos tecnológicos e científicos, são consideradas pseudociências, que basicamente são ideias que se dizem reais, mas não tem nenhum embasamento científico que possam comprová-las, ou seja, falsa ciência. Apesar disso, são usadas com linguagem convincente de que são sim, comprovadas pela ciência e são, por isso, facilmente espalhadas e usadas por toda parte. Muitas pessoas gastam seu dinheiro e até uma parte da vida consumindo produtos provenientes de pseudociências. A falta do senso crítico, ou, a sedução da ideia que parece milagrosa, não faz com que a ideia de duvidar da validade do que está sendo oferecido seja posta em prática.

A famosa frase "a ignorância é uma benção", é perfeitamente colocada em prática quando não nos damos o trabalho de duvidar, questionar e reelaborar nossos pensamentos e até mesmo o que lemos em livros e revistas ou acessamos através das 
redes sociais. Muitos dos equívocos de pensamento acontecem porque não nos damos conta da existência deles, por isso a frase da ignorância. Para ajudar a combater esses equívocos, precisamos conhecer quem são eles, para isso, se torna fundamental falarmos falácias argumentativas.

As falácias, derivadas do latim fallere, são argumentos que parecem ser muito convincentes, porém, são enganadoras. Segundo Doro $(2016$, p.8) "não quer dizer que os argumentos falaciosos são sempre projetados para enganar; na maior parte das vezes, eles resultam de um engano involuntário, uma falha não proposital de raciocínio que ilude, inclusive, o próprio autor do argumento". Toda falácia é um mau argumento, mas nem todo argumento é uma falácia, por isso, precisamos reconhecer os principais argumentos ruins para tentarmos fugir deles e construir bons argumentos críticos e reflexivos. A seguir, serão apresentadas algumas das falácias mais usadas.

Falácia do apelo à autoridade: a maioria dos trabalhos acadêmicos feitos na universidade ou mesmo nas escolas é sempre baseada em alguma teoria que já foi escrita por algum autor, e, geralmente, esse autor é um especialista no assunto. Para escrever o presente texto sobre alfabetização científica, por exemplo, precisamos recorrer a argumentos de estudiosos reconhecidos da área de alfabetização científica para basear nossos argumentos. Caso fosse usada a argumentação de uma celebridade da música popular brasileira para tal, estaríamos cometendo apelo à autoridade, pois essa celebridade não é autoridade no assunto em questão. Essa categoria de estratégia argumentativa é facilmente encontrada em propagandas na televisão, onde vemos a marca de pasta de dente sendo qualificada pelo jogador de futebol, Neymar.

Por vezes as pseudociências utilizam a falácia do apelo à autoridade, como quando alguém com titulação acadêmica mais elevada, como mestre ou doutor, aparece trazendo alguma informação que sustente aspectos de um conhecimento pseudocientífico, a exemplo de que vacinas são prejudiciais ou causam autismo. Em geral, é possível observar que ou o colocado por essa autoridade foi tirado de contexto, ou não possui critérios suficientes para ser considerado científico.

Falácia da rampa escorregadia: como o nome sugere, serve para a argumentação que desliza de um lugar e acaba parando em outro, por vezes, bem exagerado. Ela acontece no momento em que "uma sequência de eventos é apresentada como 
consequência inevitável da aceitação de uma posição inicial, sem que haja qualquer evidência de que isso realmente vá acontecer" (DORO, 2016, p. 42). Um exemplo prático: alguém pode tentar convencer um amigo de que ele não pode consumir refrigerante em excesso, pois a bebida contém estimulantes que viciam, logo, terá um momento em que ele sentirá necessidade de recorrer a outras bebidas viciantes, e por fim, estará viciado em drogas pesadas. Apesar de parecer um argumento exagerado, muitas vezes não nos damos conta que estamos cometendo ou concordando com esta falácia.

Movimentos pseudocientíficos que pregam a proximidade do fim do mundo, costumam incorrer na falácia da rampa escorregadia cada vez que um desastre natural ou humanitário acontece, como se fosse mais um sinal do apocalipse ou juízo final. Durante os primeiros meses da pandemia provocada pelo coronavírus, não faltaram pessoas alegando que esta seria um castigo divino por intercorrências no campo da moral relacionada às suas crenças pessoais.

Dois erros fazem um acerto: essa falácia consiste na tentativa de justificar um comportamento questionável ou não aceito pelas leis, com outro comportamento questionável ou não aceito. Essa falácia está presente em ditos populares como "ladrão que rouba ladrão tem direito a 100 anos de perdão". Ora, se não é certo roubar algo que não é seu, o caso do ladrão que rouba outro ladrão continua sendo errado, independente da situação. Durante os primeiros meses da crise sanitária causada pelo coronavírus, houve pessoas e até mesmo autoridades populares que se recusaram a utilizar máscaras nas ruas alegando que todas as pessoas seriam uma hora ou outra contaminadas, e quem tinha que morrer pelo vírus, morreria. Esse argumento determinista e sem sentido seria para justificar a não adesão a algo que contribuiria na redução de infecções e mortes pelo Covid-19.

Ad hominem: uma das falácias mais comuns, ad hominem é a falácia que significa atacar o homem.

Além de desviar o foco da discussão, ataques pessoais desse tipo têm como intenção desqualificar o oponente. Por exemplo, em uma discussão sobre arte contemporânea, alguém reage nos seguintes termos a uma opinião: 'desconfio que você nunca visitou um museu e que tampouco fez leituras na área, por isso, seria conveniente que você guardasse suas opiniões para si' (DORO, 2016, p. 58). 
Não significa que só porque a pessoa discorda da opinião alheia que tem o direito de diminuí-la ao ponto de tirar a credibilidade da outra pessoa, afirmando que ela só pensa assim por não entender nada de arte contemporânea. Em debates políticos, é muito comum observar como cada participante do debate se porta durante suas argumentações, alguns gastam todo seu tempo atacando a pessoa e não ao argumento dela, sendo assim, quem acaba perdendo a razão, é a própria pessoa. A falácia do ad hominem também é vista sendo utilizada para sustentar pseudociências, como quando o argumento de uma pessoa é desconsiderado e invalidado simplesmente por ela ter uma opinião política diferente.

Movimentos que negam o aquecimento global, costumam atacar ativistas por outras opiniões progressistas que supostamente indicariam que estes são por isso “comunistas" e não devem ser levados a sério, o que está ligado também a falácia do Espantalho. O mesmo uso da falácia do espantalho vimos quando, nos primeiros meses da pandemia do Covid-19, pessoas de diversos países ocidentais recusaram-se a aceitar doações de máscaras e utensílios de proteção que viessem da China. $\mathrm{O}$ argumento era que essas doações estariam carregando vírus visando infectar seus países, por que foi na China onde ocorreu o primeiro epicentro de contágio se deu na China, então estes deveriam ser os criadores do vírus, em uma conspiração que teria o objetivo de espalhálo pelo mundo. A mesma desconfiança viria para uma possível vacina que seria desenvolvida por cientistas chineses. Por serem chineses, o país onde ocorreu o primeiro surto da pandemia, seriam por tanto cientistas mal-intencionados.

A falácia do Espantalho, segundo Doro (2016, p. 30) "consiste em, intencionalmente, apresentar uma versão caricaturada, distorcida ou mal construída de um argumento, de modo a poder atacá-lo com mais facilidade.”. Nesta falácia, o foco de um debate é desviado do argumento original, através do uso de um tema "espantalho". Um exemplo na ciência, é quando um defensor do criacionismo, tenta desqualificar a teoria da evolução, questionando que "se o homem evoluiu do macaco, por que ainda existem macacos?". Trata-se de um espantalho porque é uma distorção caricaturada de um elemento presente na teoria da evolução. A teoria não explica que o homem tenha evoluído do macaco, mas sim que compartilha um ancestral comum com os macacos, o que é bem diferente. 
Devido à possibilidade de gerar uma compreensão mais aprofundada sobre argumentos, Sagan (2006), considera que o estudo das falácias lógicas é como adquirir um kit de ferramentas. Como qualquer instrumento, esse kit pode ser mal-empregado ao ser aplicado fora de contexto, mas quando aplicado judiciosamente, pode ser muito útil para avaliar argumentos, em especial os que dizem respeito a temas científicos.

\title{
4. LÓGICA ARGUMENTATIVA E ALFABETIZAÇÃO CIENTÍFICA
}

Carl Sagan (2006), considera que um dos problemas que colabora para a disseminação de movimentos pseudocientíficos, é a facilidade que se tem de criar informações equivocadas, frente a complexidade que é a produção científica:

\begin{abstract}
A pseudociência é mais fácil de ser inventada que a ciência, porque os confrontos perturbadores com a realidade - quando não podemos controlar o resultado da comparação — são evitados mais facilmente. Os padrões da argumentação, o que passa por evidência, são muito menos rigorosos. Em parte, por essas mesmas razões, é muito mais fácil apresentar a pseudociência ao público em geral do que a ciência (SAGAN, 2006, s/p.).
\end{abstract}

Se os níveis de argumentação das pseudociências são mais fracos do que o exigido na cultura científica, focar no ensino de lógica argumentativa pode ser então uma saída para preparar os jovens criticamente para o contato com a desinformação.

Sasseron (2015), coloca que a argumentação dialética, como estratégia de ensino de ciências, pode evidenciar as perspectivas de construção de entendimento de conceitos e ideias, explicitar divergências e colocar ideias pessoais em confronto, de modo a analisá-las. Para a autora, um trabalho argumentativo de envolvimento com a linguagem científica pode ser conseguido através da comunicação de ideias, avaliação de problemas e processos construídos ao tentar resolvê-los:

Essa perspectiva da argumentação coloca em evidência aspectos epistêmicos que superam o caráter linguístico e oferecem respaldo para que características próprias de uma área de conhecimento possam se fazer presentes. Para nosso caso, nas ciências da natureza, a construção de argumentos deflagra a busca por entendimento, validação e aceitação de proposições e processos de investigação em que justificativas e condições de contorno e de refutação precisam ser explicitadas (SASSERON, 2015, p. 60).

Dessa forma, a Alfabetização Científica aliada à Argumentação e ao Ensino por Investigação, pode promover a concretização do estabelecimento de uma cultura científica escolar. Sasseron (2015, p. 61) nos mostra que

[...] a linguagem argumentativa tem o intuito central de delimitar o contexto de validade de uma afirmação, explicitando condições de contorno e condições de exceção associadas ao fato em alegação. Tanto a investigação quanto a argumentação compõem aspectos do fazer científico e, por isso, correspondem a elementos da cultura científica.

Continua a autora mencionando que:

Recebido em: 30/05/2021

Aceite em: 13/08/2021 
Ao mesmo tempo, investigação e argumentação têm sido utilizadas como formas de tratar assuntos científicos em sala de aula. Explicitam-se não apenas como metodologias ou abordagens educativas, ocupando o papel de colocar em evidência aspectos culturais do fazer científico. Podem demarcar de modo mais claro o que é próprio da disciplina escolar relacionado às "ciências da natureza". Assim, correspondem a elementos da cultura escolar.

Partindo disso, pode-se propor que o estudo de lógica argumentativa no ensino formal, como o discernimento de falácias, pode ser uma forma de contribuir na tarefa de Alfabetização Científica, que junto ao Ensino por Investigação, torna-se essencial para a formação dos jovens para o mundo atual. Nesse sentido, destaca-se que a Alfabetização Científica, com expressa por Monteiro, Rolando e Teixeira (2021), está diretamente relacionado com o desenvolvimento das capacidades de ler o mundo a partir de uma linguagem científica, apropriando-se dela para participar das discussões que buscam maneiras de aperfeiçoá-las.

Perspectiva que é corroborado por Chassot (2000) ao mencionar que a alfabetização científica representa um conjunto de conhecimentos que deve, não apenas facilitar aos sujeitos a leitura do mundo onde vivem, mas uma leitura capaz de identificar a necessidade de transformá-lo, e transformá-lo para melhor. No seu entendimento a alfabetização científica significa uma espécie de empoderamento dos estudantes, para que se tornem agentes da transformação de sua realidade. A apropriação do conhecimento, em particular no de natureza científica, fornecerá os instrumentos necessários para a articulação e construção do conhecimento que poderão levar a ações transformadoras. Segue o autor mencionando que o ensino de Ciências deve estar alinhado com essa perspectiva, possibilitando que sua linguagem seja compreendida pelos estudantes e facilite o seu entendimento do mundo.

Esse entendimento de Alfabetização Cientifica remete ao anunciado por Shen (1975) de que existe três noções de Alfabetização Científica. Uma denominada de "alfabetização científica prática" vinculada a possibilitar ao sujeitos a resolução de problemas de forma imediata, estando associado a problemas básicos e vinculados ao seu cotidiano. A "alfabetização científica cívica" que possibilita ao cidadão ser mais atento para a ciência e seus impactos, comprometendo-se assim com a formação para a tomada de decisões mais bem informada. Por fim, tem-se a "alfabetização científica cultural" que é, em geral, associada à pequena parcela da população, pois vincula-se aos interesses pessoais, ao saber sobre ciência de maneira mais aprofundada. 
Nessa perspectiva, a Alfabetização Científica caminha na direção da argumentação e do ensino por investigação, estando associado a importância de instigar a curiosidade nos alunos por meio de atividades variadas que os levem a perceber que a Ciência tem papel fundamental em suas vidas, indo além de conceitos estagnados e historicamente construídos. O ensino de Ciências, quando orientado por um processo de alfabetização científica, favorece ao aluno estabelecer um diálogo com o mundo, uma interlocução com as outras áreas do conhecimento, o desenvolvimento de atitudes e pensamentos que permita ampliar sua visão de mundo.

\section{CONSIDERAÇÕES FINAIS}

Vivemos em um mundo que está mudando o tempo inteiro, as relações são líquidas, as pesquisas sobre um determinado assunto logo ficam obsoletas, novas descobertas são feitas, novas verdades são criadas. Perdidos em meio a tanto caos, nos vemos obrigados a tomar decisões e pensar rapidamente sobre o que comer, o que fazer no trabalho, sobre o tema do artigo da faculdade, sobre o assunto que está bombando no noticiário, sobre a descoberta da cura de uma doença, enfim, sobre todas as esferas da vida. Caso não conseguirmos analisar o que nos chega em forma de argumentação verbal ou não verbal, acabaremos seguindo o caminho que nos dizem ser o certo. A possibilidade de um caminho, apresentamos até aqui denominando-o de estudo da lógica.

Não é novidade que são feitas pesquisas nas áreas de ciências humanas e exatas sobre as contribuições do estudo da lógica no desenvolvimento do raciocínio e pensamento reflexivo no ser humano. Matthew Lipman (2008) foi um dos precursores na área da filosofia que se debruçou em pesquisas com estudantes adolescentes e universitários que estavam sendo apresentados à lógica com o objetivo de construírem o pensar crítico. Para ele, o pensar crítico é "o pensamento que 1) facilita o julgamento, pois 2) se fundamenta em critérios, 3) é autocorretivo, e 4) é sensível ao contexto" (LIPMAN, 2008, p. 172). Sendo assim, resumidamente as pesquisas de Lipman (2008) apontaram que a diferença entre o grupo que não estudou e o que estou lógica foi significativa em diversos âmbitos da vida dos estudantes, inclusive anos depois, quando estes já estavam em níveis superiores de estudos.

Recebido em: 30/05/2021

Aceite em: 13/08/2021 
A partir do exposto, consideramos que o estudo de lógica argumentativa pode vir a colaborar com os processos de enculturação ou alfabetização científica em jovens e crianças, ajudando a desenvolver pensamento crítico e reflexivo frente às artimanhas pseudocientíficas tão disseminadas na contemporaneidade. Isso encontra respaldo no anunciado por Borges e Lima (2000) de que na perspectiva construtivista associada ao ensino e a aprendizagem, está o desenvolvimento da competência argumentativa. Os autores inferem que perspectivas pedagógicas como o Educar pela Pesquisa e Educação para Pesquisa, são exemplos de propostas que evidenciam a construção de argumentos como etapa fundamental da aprendizagem o que leva o estudante a se tornar mais autônomo e a ser protagonista de sua aprendizagem.

\section{REFERÊNCIAS}

BRASIL. Ministério da Educação. Secretaria de Educação Fundamental. Programa de desenvolvimento profissional continuado. Parâmetros em ação: Primeiro e segundo ciclos do ensino fundamental (1a a 4a séries). Brasília: 1997.

BRASIL. Ministério da Educação. Secretária de Educação Fundamental. Base Nacional Curricular Comum. Brasília: 2018.

BORGES, Thelma D. B.; LIMA, Valderez M. R. A educação pela pesquisa como abordagem facilitadora da argumentação dialógica. Revista Insignare Scientia, v. 3, n. 3, p. 25 -

BUNGE, Mario. What is science? Does it matter to distinguish it from pseudoscience? A reply to my commentators. New Ideas in Psychology, v. 9 n. 2, p. 245-283, 1991.

CHASSOT, Ático. Alfabetização científica: questões e desafios para a educação. Ijuí: Ed. Unijuí, 2000.

COPI, Irving M. Introdução à lógica. 2 ed. Rio de Janeiro: Editora Mestre, 1981.

DOBELLI, Rolf. A arte de pensar claramente: como evitar as armadilhas do pensamento e tomar decisões de forma mais eficaz. 2. ed. Rio de Janeiro: Objetiva, 2014.

DORO, Marcelo J. Guia ilustrado das falácias: 34 maus argumentos a serem evitados. Passo Fundo: Sapo Morra, 2016.

FRANCELIN, Marivalde Moacir. Ciência, senso comum e revoluções científicas: ressonâncias e paradoxos. Ciência da Informação, v. 33, n. 3, p. 26-34, 2004.

Recebido em: 30/05/2021

Aceite em: 13/08/2021 
HANSSON, Sven Ove. Science and pseudocience. The Stanford Encyclopedia of Philosophy, $2017 . \quad$ Disponível em: <https://plato.stanford.edu/archives/sum2017/entries/pseudo-science/> Acesso em: 30 de Jan. de 2020.

HERE BE DRAGONS: An Introduction to Critical Thinking. Escrito e apresentado por: Brian Dunning, 2013. Disponível em: <https://www.youtube.com/watch?v=752V173e31o>. Acesso em: 20 de jan. de 2020.

KAHNEMAN, Daniel. Rápido e devagar: duas formas de pensar. Rio de Janeiro: Objetiva, 2012.

LIPMAN, Matthew. Uma definição funcional do pensar crítico. In: LIPMAN, Matthew. O pensar na educação. 4 ed. Petrópolis: Vozes, 2008. p. 169-185.

MENESES, João Paulo. Sobre a necessidade de conceptualizar o fenómeno das fake news. (OBS*) Observatório, número especial, p. 37-53, 2018.

MONTEIRO, Marco Aurélio A.; ROLANDO, Rodolfo M.; TEIXEIRA, Danielli Silva N. O impacto de mostras científicas no processo de alfabetização científica de crianças da educação infantil, Revista Insignare Scientia, v. 4, n. 4, p. 114-136, 2021.

ROSA, Cleci T. Werner; ROSA, Álvaro Becker; UZEDA, Vinicius F. Intervenções didáticas pautadas pela alfabetização e letramento científico: Estudo envolvendo pesquisas no campo da educação em ciências. Revista REPPE, v. 3, n. 1, p. 125-147, 2019.

SAGAN, Carl. O mundo assombrado por demônios: a ciência vista como uma vela no escuro. Editora Companhia de Bolso, 2006. Livro eletrônico (ePUB), não paginado.

SASSERON, Lucia Helena; CARVALHO, Anna Maria P. Alfabetização científica: uma revisão bibliográfica. Investigações em Ensino de Ciências, v. 16, n. 1, p. 59-77, 2011.

SASSERON, Lúcia Helena. Alfabetização Científica, Ensino por Investigação e Argumentação: relações entre Ciências da Natureza e escola. Ensaio: Pesquisa em Educação em Ciências, v. 17, p. 49-67, 2015.

SHEN, Benjamin SP. Views: Science Literacy: Public understanding of science is becoming vitally needed in developing and industrialized countries alike. American Scientist, v. 63, n. 3, p. 265-268, 1975.

Recebido em: 30/05/2021

Aceite em: 13/08/2021 